TITLE:

\title{
Production of ethanol from mannitol by the yeast strain Saccharomyces paradoxus NBRC 0259.
}

\section{$\operatorname{AUTHOR}(S):$}

Ota, Anri; Kawai, Shigeyuki; Oda, Hiroshi; Iohara, Keishi; Murata, Kousaku

\section{CITATION:}

Ota, Anri ...[et al]. Production of ethanol from mannitol by the yeast strain Saccharomyces paradoxus NBRC 0259.. Journal of bioscience and bioengineering 2013, 116(3): 327-332

\section{ISSUE DATE:}

2013-09

URL:

http://hdl.handle.net/2433/182901

\section{RIGHT:}

(C) 2013 The Society for Biotechnology, Japan. Published by Elsevier B.V.; This is not the published version. Please cite only the published version.; この論文は出版社版でありません。引用の際には出版社版を ご確認ご利用ください。 
1 Title

2 Production of ethanol from mannitol by the yeast strain Saccharomyces

3 paradoxus $\mathrm{NBRC} 0259$

4

5 Running title

6 PRODUCTION OF ETHANOL FROM MANNITOL

7

8 Author names and affiliations

9 Anri Ota, ${ }^{1}$ Shigeyuki Kawai, ${ }^{1}$ Hiroshi Oda,${ }^{2}$ Keishi Iohara, ${ }^{2}$ and Kousaku Murata ${ }^{1 *}$

10

11 Laboratory of Basic and Applied Molecular Biotechnology, Division of Food and

12 Biological Science, Graduate School of Agriculture, Kyoto University, Uji, Kyoto

13 611-0011, Japan ${ }^{1}$ and Maruha Nichiro Holdings, Inc. 16-2, Wadai, Tsukuba, Ibaraki,

14 300-4295, Japan ${ }^{2}$

15

$16 *$ Correspondence author.

$17 \quad$ Tel: +8177438 3766; Fax: +81774383767 .

18 E-mail: kmurata@kais.kyoto-u.ac.jp (K. Murata).

19

20 Key words.

21 macroalgae; yeast; mannitol; ethanol; flocculation; Saccharomyces paradoxus 


\section{ABSTRACT}

2

3 Mannitol is a promising marine macroalgal carbon source. However, organisms that

4 produce ethanol from mannitol are limited; to date, only the yeast Pichia angophorae

5 and the bacterium Escherichia coli KO11 have been reported to possess this capacity. In

6 this study, we searched a yeast strain with a high capacity to produce ethanol from

7 mannitol and selected Saccharomyces paradoxus NBRC 0259 for its ability to produce

8 ethanol from mannitol. This ability was enhanced after a 3-day cultivation of this strain

9 in medium containing mannitol; the enhanced strain was renamed $S$. paradoxus NBRC

10 0259-3. We compared the ability of strain NBRC 0259-3 to produce ethanol from

11 mannitol and glucose, under several conditions, with those of $P$. angophorae and E. coli

12 KO11. As a result, we concluded that S. paradoxus NBRC 0259-3 strain is the most

13 suitable yeast strain for the production of ethanol from mannitol.

14 
Marine biomass, including macroalgae, is a promising source of biofuels $(1,2)$.

2 The major advantages of macroalgae with respect to biofuels production are (i) the

3 greater productivity of macroalgae over land crops; (ii) the lack of a requirement of

4 arable land for algal cultivation, avoiding irrigation of water, use of fertilizer, etc.; and

5 (iii) the absence of lignin in macroalgae (2-4). Macroalgae comprise green, red, and

6 brown algae (4); high contents of carbohydrates have been reported in red and brown

7 algae. It is very important to develop a method for producing biofuels from the

8 carbohydrates in these algae.

9 The major carbohydrate constituents of brown algae are mannitol, the sugar

10 alcohol corresponding to mannose (5), and alginate, a linear polysaccharide consisting

11 of two monosaccharides, $\beta$-D-mannuronate (M) and its C5 epimer $\alpha$-L-guluronate $(\mathrm{G})$,

12 in which the two monosaccharides are arranged in three different configurations: polyM,

13 polyG, and heteropolymeric random sequences (polyMG) (6). The brown alga

14 Laminaria japonica contains up to $30 \%$ mannitol and $25 \%$ alginate; these and

15 subsequent figures represent percentage of dry weight (7). Zubia et al. reviewed the

16 contents of mannitol (up to $33 \%$ ) and alginate (up to $40 \%$ ) in several brown algae of

17 genera Sargassum and Turbinaria (8). Horn et al. also reported that the brown alga

18 Laminaria hyperborea contains 25\% mannitol (9).

19 In order to utilize brown algae as a source for bioethanol, it will be necessary

20 to develop systems for production of ethanol from both mannitol and alginate. Two

21 such systems have been established (10). The first of these utilizes the ethanologenic

22 bioengineered Sphingomonas sp. strain A1 (ethanologenic strain A1) that can produce

$2313 \mathrm{~g} / \mathrm{L}$ ethanol from alginate (10). Unfortunately, Sphingomonas sp. strain A1 is not

24 able to assimilate mannitol (11). The other established system utilizes a bioengineered 
1 ethanologenic Escherichia coli strain that is able to produce $37 \mathrm{~g} / \mathrm{L}$ ethanol from brown

2 algae (kombu; Saccharina japonica) containing a mixture of mannitol and alginate (12).

Despite the higher yield in the bacterial system, bacteria are generally sensitive

4 to ethanol $(9,13)$; therefore, yeast is considered to have several advantages over

5 ethanologenic bacteria, including high tolerance to ethanol and other inhibitory

6 compounds (14). Two bacterial strains, Zymobacter palmae and E. coli KO11, can

7 produce $\sim 13$ and $26 \mathrm{~g} / \mathrm{L}$ ethanol from mannitol, respectively; however, both bacteria are

8 sensitive to $50 \mathrm{~g} / \mathrm{L}$ ethanol $(9,13)$. Therefore, it would be ideal to establish a system for

9 ethanol production from alginate and mannitol that utilizes a bioengineered yeast, e.g.

10 Saccharomyces cerevisiae.

11 As an initial step, we envisioned a two-step fermentation in which alginate is

12 first converted to ethanol by the ethanologenic strain A1, and the remaining mannitol is

13 then converted to ethanol by yeast. Ethanol has been produced from mannitol by some

14 yeast strains, e.g., S. cerevisiae polyploid strain BB1 (5 g/L) and Pichia angophorae

$15(14.4 \mathrm{~g} / \mathrm{L})(9,15,16)$. By contrast, however, other $S$. cerevisiae strains, e.g., polyploid

16 BB2, haploid S288C, and haploid Sc41 YJO, are unable to assimilate mannitol for

17 growth $(15,17)$. Therefore, we decided to search for yeast suitable for production of

18 ethanol from mannitol.

19

20 MATERIALS AND METHODS

Microorganisms

The yeast strains used in this study are listed in Table 1. Ethanologenic

24 Sphingomonas sp. strain A1 (EPv104), carrying eight copies of the Zymomonas mobilis 
1 pyruvate carboxylase gene and one copy of the Z. mobilis alcohol dehydrogenase gene

2 on plasmid pKS13, was described previously (10). E. coli strain KO11 (ATCC 55124)

3 was purchased from the American Type Culture Collection. P. angophorae (CBS5830)

4 (9) was purchased from CBS-KNAW Fungal Biodiversity Centre. These strains were

5 stocked at $-80^{\circ} \mathrm{C}$ in the presence of $17 \%(\mathrm{v} / \mathrm{v})$ glycerol.

6

$7 \quad$ Media

Complete synthetic medium without carbon source (SC-C) (pH 5.6) consisted

9 of the following (in $\mathrm{g} / \mathrm{L}$ ): yeast nitrogen base w/o amino acid (Becton, Dickinson and 10 Company, Sparks, MD), 6.7; -Leu Do supplement (Clontech, Palo Alto, CA), 0.69; and

11 L-Leucine (Nacalai Tesque, Kyoto, Japan), 0.1. SC-C medium was supplemented with

$1220 \mathrm{~g} / \mathrm{L}$ glucose (for SC medium), $20 \mathrm{~g} / \mathrm{L}$ mannitol (for SM medium) or 3\% (v/v)

13 glycerol (for SG medium). Yeast extract/peptone medium (YP) ( $\mathrm{pH}$ 5.6) consisted of

14 the following (in $\mathrm{g} / \mathrm{L}$ ): yeast extract, 10; tryptone, 20. The YP medium was

15 supplemented with $20 \mathrm{~g} / \mathrm{L}$ glucose (for YPD medium), $20 \mathrm{~g} / \mathrm{L}$ mannitol (for YPM medium), or 3\% (v/v) glycerol (for YPG medium), until otherwise stated. LB medium

17 ( $\mathrm{pH}$ 7.2) consisted of the following (in $\mathrm{g} / \mathrm{L}$ ): yeast extract, 5 ; tryptone, $10 ; \mathrm{NaCl}, 10 . \mathrm{LB}$

18 medium was supplemented with $20 \mathrm{~g} / \mathrm{L}$ mannitol (for LBM medium) and $20 \mathrm{~g} / \mathrm{L}$

19 glucose (for LBD medium). Solid media were generated by addition of $20 \mathrm{~g} / \mathrm{L}$ agar

20 (Nacalai Tesque) to the appropriate liquid media. YP and LB media were sterilized by

21 autoclaving the base media separately from the carbon sources. Stocks of 10-fold

22 concentrated YP and 10-fold concentrated LB were sterilized by filtration with $0.2-\mu \mathrm{m}$

23 pore size. When necessary, cells were grown under anaerobic conditions using the

24 AnaeroPack Anaero (Mitsubishi Gas Chemical, Tokyo, Japan). 
$1 \quad \rho^{0}$ yeast strains were produced by treating yeast with $25 \mu \mathrm{g} / \mathrm{ml}$ ethidium

2 bromide (18). In S. cerevisiae, strains completely lacking mitochondrial genomes are

3 denoted $\rho^{0}$, whereas strains harboring intact mitochondrial genomes are $\rho^{+}(18) . \rho^{0}$

4 strains fail to grow on YPG or YPM medium, which contain only nonfermentable

5 carbon sources, due to their inability to perform respiration.

To prepare an A1 supernatant, ethanologenic Sphingomonas sp. strain A1

7 (EPv104) was cultured for 3 days at $30^{\circ} \mathrm{C}$ on a shaker (Personal Lt-10F, Taitec, Tokyo,

8 Japan) at 95 strokes per minute ( $\mathrm{spm}$ ) in a liquid medium containing $50 \mathrm{~g} / \mathrm{L}$ alginate as

9 described (10). After 3 days of cultivation, the culture was centrifuged at 20,000 $\times g$ for

$1010 \mathrm{~min}$. The $\mathrm{pH}$ of the resulting supernatant was adjusted to $\mathrm{pH} 5.8$ using $\mathrm{HCl}$, yielding

11 the "A1 supernatant". YP-A1 medium consisted of $22.5 \mathrm{ml} \mathrm{A1}$ supernatant and $2.5 \mathrm{~mL}$

12 10-fold concentrated YP ( $\mathrm{pH}$ 5.8). YP2M-A1 and YP5M-A1 media were $25 \mathrm{ml}$ YP-A1

13 media containing $0.5 \mathrm{~g}(20 \mathrm{~g} / \mathrm{L})$ and $1.25 \mathrm{~g}(50 \mathrm{~g} / \mathrm{L})$ mannitol, respectively. LB5M-A1

14 medium contained $22.5 \mathrm{ml} \mathrm{A} 1$ supernatant, $2.5 \mathrm{ml} \mathrm{10-fold} \mathrm{concentrated} \mathrm{LB,} \mathrm{and} 1.25 \mathrm{~g}$

$15 \quad(50 \mathrm{~g} / \mathrm{L})$ mannitol.

\section{Cultivation}

For cultivation of ethanologenic yeasts in liquid medium, fresh cells grown on

19 solid YPM media were suspended in sterilized water (SDW) and added to $50 \mathrm{ml}$ liquid

20 YPM medium to give an $\mathrm{OD}_{600}$ of 0.1 . Cultivation was conducted at $30^{\circ} \mathrm{C}$ in a $100 \mathrm{ml}$

21 Erlenmeyer flask on a shaker (Personal Lt-10F) at $95 \mathrm{spm}$, unless otherwise stated.

22 After 1 day of cultivation, cells were collected, washed once with SDW, suspended in

23 SDW, and added to fresh $50 \mathrm{ml}$ YPM or YPD medium to give an $\mathrm{OD}_{600}$ of 0.1 ;

24 cultivation was continued at $30^{\circ} \mathrm{C}$ and $95 \mathrm{spm}$. For cultivation of E. coli KO11, LBM 
1 and LBD were used instead of YPM and YPD. E. coli cells were washed and suspended

2 in SDW containing $10 \mathrm{~g} / \mathrm{L} \mathrm{NaCl}$, and were cultured at $30^{\circ} \mathrm{C}$ and $95 \mathrm{spm}$. When

3 YP2M-A1, YP5M-A1, and LB5M-A1 media were used, cultivation was conducted in

$425 \mathrm{ml}$ liquid medium in a $50 \mathrm{ml}$ Erlenmeyer flask on a shaker (Personal Lt-10F) at 95

5 spm and $30^{\circ} \mathrm{C}$.

6

$7 \quad$ Analytical methods

Ethanol concentrations in culture supernatants obtained by centrifugation ( 5

$9 \min , 20,000 \times g, 4^{\circ} \mathrm{C}$ ) were determined using the ethanol assay F-kit (Roche Diagnostics,

10 Basel, Switzerland). Concentrations of glucose and mannitol were determined using an

11 HPLC equipped with an Aminex HPX-87H column $(300 \times 7.8 \mathrm{~mm}$; Bio-Rad $)$ and a

12 RID-10A detector (Shimadzu, Kyoto, Japan). Other conditions were as follows: effluent,

13 filtered and degassed $5 \mathrm{mM} \mathrm{H}_{2} \mathrm{SO}_{4}$; flow rate, $0.65 \mathrm{ml} \mathrm{min}^{-1}$; and column temperature,

$14 \quad 65.5^{\circ} \mathrm{C}$. Detection limits for glucose and mannitol were $0.2 \mathrm{~g} / \mathrm{L}$.

\section{RESULTS AND DISCUSSION}

\section{Identification of yeast strains producing ethanol from mannitol}

SC and SM media are synthetic media containing each of $20 \mathrm{~g} / \mathrm{L}$ glucose and $20 \mathrm{~g} / \mathrm{L}$ mannitol as a carbon source, respectively; SC-C is a synthetic medium containing no carbon source. To identify yeast strains capable of producing ethanol

22 from mannitol, we first searched for yeast strains that could utilize mannitol for growth.

23 Of the 45 strains tested, 15 grew better on SM solid media than on SC-C solid or liquid 24 media (Table 1). Among these 15 strains, six (Saccharomyces paradoxus NBRC 0259, 
1 Kuraishia capsulata NBRC 0721, Kuraishia capsulata NBRC 0974, Ogataea

2 glucozyma NBRC 1472, Ogataea minuta NBRC 1473, and Debaryomyces hansenii 3 NBRC 0794) produced at least $26 \mathrm{mg} / \mathrm{L}$ ethanol in SM liquid medium and at least 1.0

$4 \mathrm{~g} / \mathrm{L}$ ethanol from SC liquid medium without shaking (i.e., at $0 \mathrm{spm}$ ) (Fig. 1A). Of these

5 six strains, $S$. paradoxus strain NBRC 0259 produced the highest amount of ethanol

6 from mannitol in this condition (Fig. 1A) and in YPM liquid medium at $95 \mathrm{spm}$ (Fig.

7 1B, Table 2) (19). Moreover, S. paradoxus strain NBRC 0259 consumed the highest

8 amount of mannitol, exhibited the highest ethanol productivity and yield among these

9 six strains in YPM liquid medium at $95 \mathrm{spm}$ (Table 2), and also exhibited the highest 10 tolerance to $50 \mathrm{~g} / \mathrm{L}$ ethanol (Fig. 1C) (19).

11 Ethanologenic strain A1 can produce ethanol from alginate, but not from 12 mannitol (10). An ideal yeast strain would be capable of producing ethanol from 13 mannitol after the ethanologenic strain A1 had finished producing ethanol from alginate.

14 To identify such a strain, we cultivated the ethanologenic strain A1 in a liquid medium 15 containing $50 \mathrm{~g} / \mathrm{L}$ alginate for 3 days and centrifuged to obtain the supernatant (A1 supernatant) which contained $\sim 10.0 \mathrm{~g} / \mathrm{L}$ ethanol and other unknown metabolic

17 compounds. We then investigated whether the six yeast strains could produce ethanol 18 from mannitol in YP2M-A1 (A1 supernatant plus YP and 20g/L mannitol) medium as 19 described in MATERIALS AND METHODS. As shown in Fig. 1D, only S. paradoxus

20 NBRC 0259 produced ethanol under this severe condition, suggesting that this strain is 21 highly tolerant to the toxic compounds generated by ethanologenic strain A1 (Fig. 1D).

22 Therefore, we selected S. paradoxus NBRC 0259 for further study.

24 Ethanol production from mannitol by $S$. paradoxus NBRC 0259 
2 the presence of glucose (Fig. 2A), whereas the other five strains did not. Yeast

3 flocculation is a reversible, non-sexual cell aggregation in which cells adhere to each

4 other in a $\mathrm{Ca}^{2+}$-dependent manner to form flocs; it has been used in the brewing industry

5 as a simple and cost-effective way to separate yeast cells from fermentation products

6 (20). S. paradoxus strains have been isolated from natural and fermentative habitats

7 (e.g., tree bark, oak tree bark, pulque fermentation, and wine fermentation) and are

8 tolerant to ethanol $(21,22)$. S. paradoxus has also been regarded as an attractive model

9 for population-genetic and genomic studies (23).

The polyploid S. cerevisiae strain BB1 needs oxygen to utilize mannitol, and

11 exhibits high respiratory activity when growing in SM medium (15). Oxidation of

12 mannitol to fructose by mannitol dehydrogenase is predicted to produce excess NADH

13 (Fig. 2B); hence, it has been proposed that yeasts require respiration in order to

14 assimilate mannitol (15). As shown in Fig. 2C, S. paradoxus NBRC0259 did not grow on SM medium under anaerobic conditions irrespective of the presence or absence of intact mitochondria, whereas a $\rho^{0}$ strain that lacks the mitochondrial genome failed to

17 grow on SM medium even under aerobic conditions, demonstrating that S. paradoxus

18 NBRC0259 requires oxygen and respiration to assimilate mannitol (19).

S. paradoxus NBRC 0259 maintained on YPD solid medium tended to lose the capacity to grow on YPM or YPG solid medium (five of six single colonies tested).

21 Therefore, S. paradoxus NBRC $0259 \rho^{+}$strain was streaked from glycerol stock on

22 YPM solid medium and grown on this medium, rather than YPD solid medium, in order

23 to avoid losing its capacity to grow on YPM or YPG medium, i.e., to avoid becoming $\rho^{0}$.

24 To monitor the effects of recent handling, S. paradoxus NBRC 0259 grown on YPM 
1 solid medium was pre-cultured in either YPM or YPD liquid medium, and then further

2 cultured in YPM liquid medium. The ethanol productivity of cells pre-cultured in YPM

3 liquid medium was significantly higher than that of cells pre-cultured in YPD liquid

4 medium (Fig. 2D; closed and open circles). Thus, we chose YPM liquid medium as the

5 medium for pre-culture.

Because $S$. paradoxus NBRC 0259 requires oxygen to assimilate mannitol, we

7 examined the effects of aeration conditions on ethanol production. S. paradoxus NBRC

80259 pre-cultured in YPM liquid medium was cultured in YPM or YPD liquid medium

9 at various shaking speeds $(0,95$, and $145 \mathrm{spm})$ (Fig. 2E). At $145 \mathrm{spm}$ in YPM medium,

10 the strain exhibited the best growth, but no ethanol production. At $0 \mathrm{spm}$ in YPM

11 medium, the strain hardly grew and produced low ethanol concentration. At $95 \mathrm{spm}$ in

12 YPM medium, the strain displayed moderate growth and the highest ethanol production.

13 Thus, moderate aeration by shaking at $95 \mathrm{spm}$ was chosen as the aeration condition for

14 production of ethanol from mannitol (19). This strain produced higher amounts of

15 ethanol from glucose than those from mannitol at 0 and $95 \mathrm{spm}$, although it flocculated

16 in YPD medium (Fig. 2A, E).

17 S. paradoxus NBRC 0259 produced ethanol less efficiently from mannitol than

18 from glucose; ethanol production began after 2 or 3 days of cultivation (Fig. 2D, E).

19 The original $S$. paradoxus NBRC 0259 cells that had been grown for 3 days in YPM

20 liquid medium were frozen in the presence of $17 \%(\mathrm{v} / \mathrm{w})$ glycerol and maintained at

$21-80^{\circ} \mathrm{C}$; this isolate was named $S$. paradoxus NBRC 0259-3. NBRC 0259-3 strain was

22 streaked from glycerol stock on YPM solid medium, grown on this medium,

23 pre-cultured in YPM liquid medium, and cultivated in YPM liquid medium at $30^{\circ} \mathrm{C}$ and

$2495 \mathrm{spm}$ to monitor the ethanol production. We observed that this strain started to 
1 produce ethanol more quickly than the original NBRC 0259 isolate (Fig. 2D; closed

2 triangles); it also flocculated in the presence of glucose (data not shown). Hence, we

3 selected NBRC 0259-3 strain for further study. We speculate that some epigenetic

4 events, making yeasts ready to assimilate mannitol, possibly occurs during initial

5 cultivation of original NBRC 0259 strain in YPM liquid medium.

6

\section{Comparisons of the capacity to produce ethanol from mannitol}

We compared the ethanol tolerance and ethanol productivity of $S$. paradoxus

9 NBRC 0259-3 with those of two other microbes previously reported to produce ethanol

10 from mannitol, P. angophorae (9) and E. coli KO11 (13). In contrast to the case of $S$.

11 paradoxus NBRC 0259, these microbes' abilities to produce ethanol from mannitol

12 were not enhanced after 3 days of cultivation in YPM or LBM (data not shown).

Among the three organisms, S. paradoxus NBRC 0259-3 exhibited maximum

14 tolerance to $50 \mathrm{~g} / \mathrm{L}$ ethanol (Fig. 3A). The three strains produced approximately the

15 same amounts of ethanol from mannitol and glucose and also exhibited approximately

16 the same productivity and yield (Fig. 3B, Table 2). However, in the presence of the A1

17 supernatant, in which ethanologenic strain A1 had produced approximately $10 \mathrm{~g} / \mathrm{L}$

18 ethanol from a liquid medium containing $50 \mathrm{~g} / \mathrm{L}$ alginate, $\mathrm{KO} 11$ did not produce ethanol

19 from mannitol, whereas both yeasts did (Fig. 3C), indicating that E. coli KO11 is

20 sensitive to the metabolites produced from alginate by ethanologenic strain A1, while

21 yeasts are tolerant. In the presence of a high concentration of glucose or mannitol (100

$22 \mathrm{~g} / \mathrm{L})$, S. paradoxus NBRC 0259-3 produced higher amount of ethanol from mannitol

23 than $P$. angophorae did and higher amount of ethanol from glucose than E. coli KO11

24 did (Fig. 3D). In the presence of both $20 \mathrm{~g} / \mathrm{L}$ glucose and $20 \mathrm{~g} / \mathrm{L}$ mannitol (total sugars, 
$140 \mathrm{~g} / \mathrm{L}$ ), all three organisms utilized mannitol to produce ethanol, although glucose was

2 consumed faster than mannitol (Fig. 3E).

Thus, S. paradoxus NBRC 0259-3 exhibited the highest tolerance to ethanol;

4 high production of ethanol from mannitol in the presence of A1 supernatant; and high

5 production of ethanol from high concentrations of glucose and mannitol (Fig. 3, Table

6 2). Based on these observations, we concluded that $S$. paradoxus NBRC 0259-3 is the

7 most suitable yeast strain for the production of ethanol from mannitol, a promising

8 marine macroalgal carbon source (19).

9

10 ACKNOWLEDGMENTS

11

12

This work was supported by the Program for Promotion of Basic Research

13 Activities for Innovative Biosciences (PROBRAIN) of Japan (to K.M.) and by the

14 Funding Program for Next Generation World-Leading Researchers (NEXT Program)

15 (to S.K.). 


\section{REFERENCES}

3 1. John, R. P., Anisha, G. S., Nampoothiri, K. M., and Pandey, A.: Micro and 4 macroalgal biomass: a renewable source for bioethanol, Bioresour. Technol., 102, 186-193 (2011).

6 2. Huesemann, M., Roesjadi, G., Benemann, J., and Metting, F. B.: Biofuels from microalgae and seaweeds, p. 165-184. In Vertès, A., Qureshi, N., Yukawa, H., and Blaschek, H. P. (ed.), Biomass to biofuels: strategies for global industries, Wiley (2010).

3. Adams, J. M., Gallagher, J. A., and Donnison, I. S.: Fermentation study on Saccharina latissima for bioethanol production considering variable pre-treatments, J. Appl. Phycol., 21, 569-574 (2009).

4. Yoon, J. J., Kim, Y. J., Kim, S. H., Ryu, H. J., Choi, J. Y., Kim, G. S., and Shin, M. K.: Production of polysaccharides and corresponding sugars from red seaweed, Adv. Mat. Res., 93-94, 463-466 (2010).

5. Horn, S. J., Aasen, I. M., and Østgaard, K.: Production of ethanol from mannitol by Zymobacter palmae, J. Ind. Microbiol. Biotechnol., 24, 51-57 (2000).

19 6. Gacesa, P.: Alginates, Carbohydr. Polym., 8, 161-182 (1988).

7. Honya, M., Kinoshita, T., Ishikawa, M., Mori, H., and Nisizawa, K.: Monthly determination of alginate, $\mathrm{M} / \mathrm{G}$ ratio, mannitol, and minerals in cultivated Laminaria Japonica, Nippon Suisan Gakkaishi, 59, 295-299 (1993).

23 8. Zubia, M., Payri, C., and Deslandes, E.: Alginate, mannitol, phenolic 
Sargassum mangarevense and Turbinaria ornata (Phaeophyta: Fucales), from Tahiti (French Polynesia), J. Appl. Phycol., 20, 1033-1043 (2008).

9. Horn, S. J., Aasen, I. M., and Ostgaard, K.: Ethanol production from seaweed extract, J. Ind. Microbiol. Biotechnol., 25, 249-254 (2000).

10. Takeda, H., Yoneyama, F., Kawai, S., Hashimoto, W., and Murata, K.: Bioethanol production from marine biomass alginate by genetically engineered bacteria, Energy Environ. Sci., 4, 2575-2581 (2011).

11. Hisano, T., Yonemoto, Y., Yamashita, T., Fukuda, Y., Kimura, A., and Murata, K.: Direct uptake of alginate molecules through a pit on the bacterial-cell surface - a novel mechanism for the uptake of macromolecules, J. Ferment. Bioeng., 79, 538-544 (1995).

12. Wargacki, A. J., Leonard, E., Win, M. N., Regitsky, D. D., Santos, C. N., Kim, P. B., Cooper, S. R., Raisner, R. M., Herman, A., Sivitz, A. B., Lakshmanaswamy, A., Kashiyama, Y., Baker, D., and Yoshikuni, Y.: An engineered microbial platform for direct biofuel production from brown macroalgae, Science, 335, 308-313 (2012).

13. Kim, N. J., Li, H., Jung, K., Chang, H. N., and Lee, P. C.: Ethanol production from marine algal hydrolysates using Escherichia coli KO11, Bioresour. Technol., 102, 7466-7469 (2011).

14. Hughes, S. R., and Qureshi, N.: Biofuel demand realization, p. 55-69. In Vertès, A., Qureshi, N., Yukawa, H., and Blaschek, H. P. (ed.), Biomass to biofuels: strategies for global industries, Wiley (2010).

15. Quain, D. E., and Boulton, C. A.: Growth and metabolism of mannitol by strains of Saccharomyces cerevisiae, J. Gen. Microbiol., 133, 1675-1684 (1987). 
1 16. Lee, H., and Schneider, H.: Ethanol production from xylitol and some other polyols by Pichia angophorae, Biotechnol. Lett., 9, 581-584 (1987).

17. Perfect, J. R., Rude, T. H., Wong, B., Flynn, T., Chaturvedi, V., and Niehaus, W.: Identification of a Cryptococcus neoformans gene that directs expression of the cryptic Saccharomyces cerevisiae mannitol dehydrogenase gene, J. Bacteriol., 178, 5257-5262 (1996).

18. Fox, T. D., Folley, L. S., Mulero, J. J., McMullin, T. W., Thorsness, P. E., Hedin, L. O., and Costanzo, M. C.: Analysis and manipulation of yeast mitochondrial genes, Methods Enzymol., 194, 149-165 (1991).

19. Kawai, S., and Murata, K.: Ethanol production from brown macroalgae, In Ueda, M. (ed.), Frontier of recycle biotechnology, CMC, Tokyo (2013). (in Japanese) (in press)

20. Zhao, X. Q., and Bai, F. W.: Yeast flocculation: New story in fuel ethanol production, Biotechnol. Adv., 27, 849-856 (2009).

21. Arroyo-Lopez, F. N., Salvado, Z., Tronchoni, J., Guillamon, J. M., Barrio, E., and Querol, A.: Susceptibility and resistance to ethanol in Saccharomyces strains isolated from wild and fermentative environments, Yeast, 27, 1005-1015 (2010).

22. Redzepovic, S., Orlic, S., Sikora, S., Majdak, A., and Pretorius, I. S.: Identification and characterization of Saccharomyces cerevisiae and Saccharomyces paradoxus strains isolated from Croatian vineyards, Lett. Appl. Microbiol., 35, 305-310 (2002).

23. Johnson, L. J., Koufopanou, V., Goddard, M. R., Hetherington, R., Schafer, S. M., and Burt, A.: Population genetics of the wild yeast Saccharomyces 
paradoxus, Genetics, 166, 43-52 (2004).

2

3

4 


\section{FIGURE LEGEND}

2

3 FIG. 1. Properties of ethanologenic yeasts. (A) Ethanol production by ethanologenic

4 yeasts cultured in $1.0 \mathrm{ml} \mathrm{SM}$ (gray bar) and SC (closed bar) liquid media without

5 shaking. Scales on left and right sides indicate concentrations of ethanol from mannitol

6 and glucose, respectively. (B) Ethanol production by ethanologenic yeasts cultured in

$750 \mathrm{ml}$ YPM liquid medium at $95 \mathrm{spm}$. (C) Ethanol tolerance of ethanologenic yeasts.

8 Yeasts were inoculated into $1.0 \mathrm{ml}$ YPM liquid medium with or without $50 \mathrm{~g} / \mathrm{L}$ ethanol

9 to give $\mathrm{OD}_{600}$ of 0.1 and grown for 1 day at $95 \mathrm{spm} . \mathrm{OD}_{600}$ of the culture with ethanol is

10 shown as relative growth, taking that of the culture without ethanol as 1.0. (D) Ethanol

11 production of ethanologenic yeasts cultured in $25 \mathrm{ml}$ YP2M-A1 liquid medium

12 (containing the A1 supernatant) at $95 \mathrm{spm}$. (A-D) Means and maximum and minimum

13 values of two independent experiments are shown. Strains (A-D): 1, diamond,

14 Saccharomyces paradoxus NBRC 0259; 2, triangle, Kuraishia capsulata NBRC 0721; 3,

15 X, Kuraishia capsulata NBRC 0974; 4, circle, Ogataea glucozyma NBRC 1472; 5, +,

Ogataea minuta NBRC 1473; 6, square, Debaryomyces hansenii NBRC 0794.

FIG. 2. Properties of $S$. paradoxus NBRC 0259. (A) $\mathrm{Ca}^{2+}$-dependent flocculation. $S$. paradoxus NBRC 0259 strain was cultured for 1 day in $5 \mathrm{ml}$ YPD or YPM liquid media, transferred to test tubes, and held for $10 \mathrm{~min}$ (left). To the culture, $500 \mathrm{mM}$ EDTA was added to reach a final concentration of $50 \mathrm{mM}$, and then the culture was vortexed and held for 10 min (center). Cells were collected, washed once with SDW, resuspended in $10 \mathrm{mM} \mathrm{CaCl}$, and held for $10 \mathrm{~min}$ (right). Flocculated NBRC 0259 cells were

24 dispersed in $50 \mathrm{mM}$ EDTA and flocculated again in $10 \mathrm{mM} \mathrm{CaCl}_{2}$, demonstrating 
$1 \mathrm{Ca}^{2+}$-dependent flocculation. (B) Reaction catalyzed by mannitol dehydrogenase (19).

2 (C) Growth of $\rho^{0}$ and $\rho^{+}$strains of $S$. cerevisiae BY4742 and S. paradoxus NBRC 0259

3 on SM and SC solid media in the presence $(+)$ or absence $(-)$ of oxygen $\left(\mathrm{O}_{2}\right)$ after 4

4 days. (D) S. paradoxus NBRC 0259 cells pre-cultured for 1 day in YPM (closed circle)

5 or YPD liquid medium (open circle), and S. paradoxus NBRC 0259-3 cells pre-cultured

6 for 1 day in YPM liquid medium (closed triangle), were inoculated to YPM liquid

7 medium and cultivated at $95 \mathrm{spm}$ for the indicated periods. (E) Effect of shaking speed

8 on ethanol production of $S$. paradoxus NBRC 0259 strain in YPM (closed symbols) or

9 YPD (open symbols) liquid medium. This strain was pre-cultured in YPM liquid medium for 1 day and further cultured in YPM liquid medium with the indicated

11 shaking speed (triangle, $145 \mathrm{spm}$; circles, $95 \mathrm{spm}$; squares, $0 \mathrm{spm}$ ). This strain produced

12 no ethanol in YPM medium at either 0 or $145 \mathrm{spm}$. (D, E) Means and maximum and

13 minimum values of two independent experiments are shown.

FIG. 3. Comparison of the ability to produce ethanol from mannitol. (A) Ethanol tolerance of the three organisms. Microbes were inoculated to $1.0 \mathrm{ml}$ YPM (1, NBRC 0259-3; 2, P. angophorae) or LBM (3, E. coli KO11) liquid medium containing 0 and

$1850 \mathrm{~g} / \mathrm{L}$ ethanol to give an $\mathrm{OD}_{600}$ of 0.1 and were grown for 1 day at $95 \mathrm{spm}$. $\mathrm{OD}_{600}$ of

19 the culture containing ethanol is shown as relative growth, taking that of the culture without ethanol as 1.0. (B) Ethanol production of NBRC 0259-3 (triangles), $P$. angophorae (squares), and E. coli KO11 (diamonds) in YPM (closed symbols) or YPD

22 (open symbols) liquid media. (C) Ethanol production by the three ethanologenic organisms as in (B) in YP5M-A1 or LB5M-A1 consisting of A1 supernatant, $50 \mathrm{~g} / \mathrm{L}$ mannitol, and YP or LB. (D) Ethanol production of NBRC 0259-3 (left, NBRC), $P$. 
1 angophorae (center, Pan), and E. coli KO11 (right, KO11) in YP plus $100 \mathrm{~g} / \mathrm{L}$ glucose

2 (open circles) or $100 \mathrm{~g} / \mathrm{L}$ mannitol (closed circles). In the case of E. coli KO11, LB was

3 used instead of YP. (E) Sugars (glucose, open circles; mannitol, closed circles) and

4 ethanol (closed squares) in cultures of the three organisms, as in (D). The organisms

5 were grown in YP (NBRC 0259-3 and P. angophorae) or LB (E. coli KO11) liquid

6 medium containing both $20 \mathrm{~g} / \mathrm{L}$ glucose and $20 \mathrm{~g} / \mathrm{L}$ mannitol (total sugars, $40 \mathrm{~g} / \mathrm{L}$ ).

7 (A-E) Means and maximum and minimum values of two independent experiments are

8 shown. 

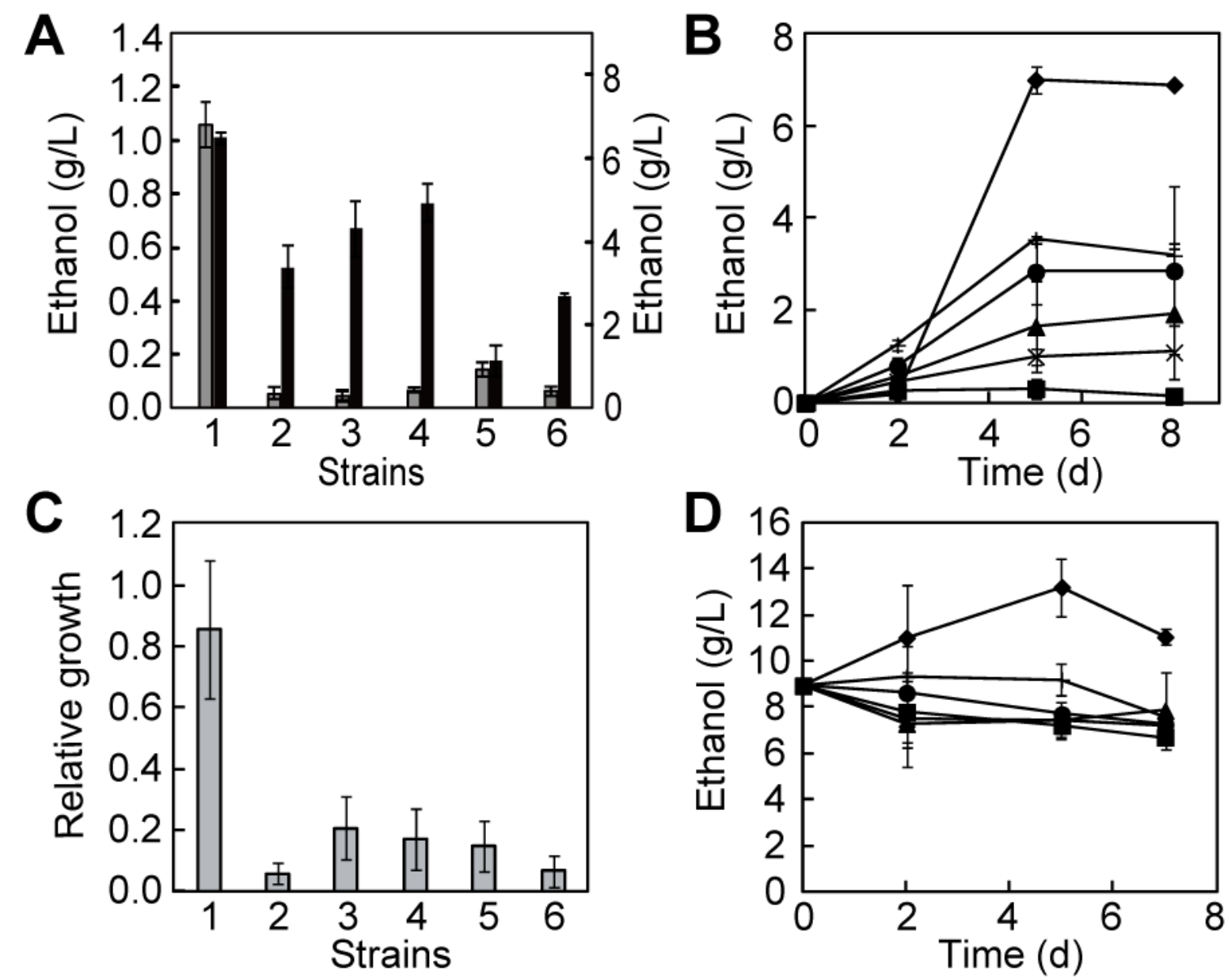

FIG. 1. 


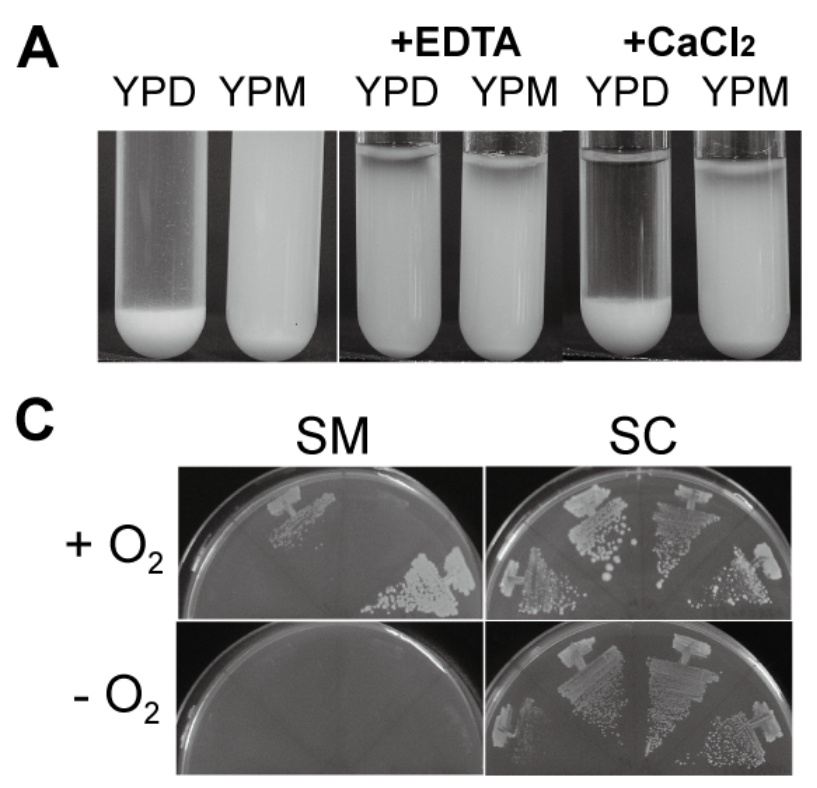

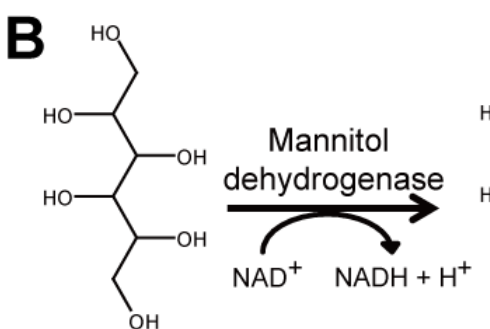

Mannitol

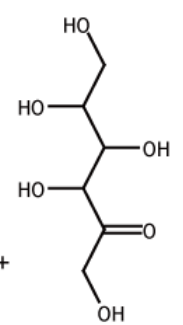

Fructose

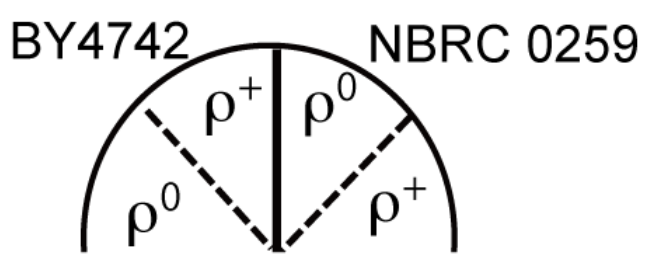

D

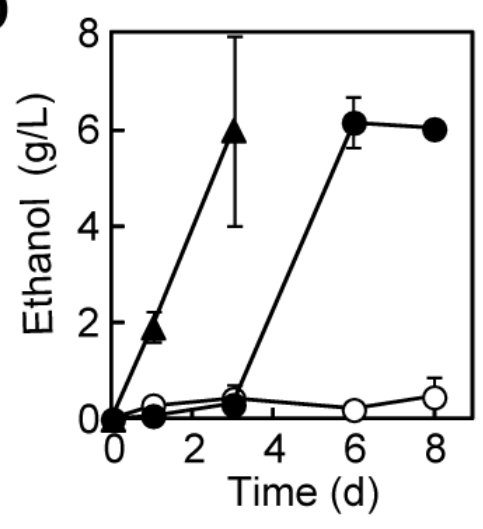

E

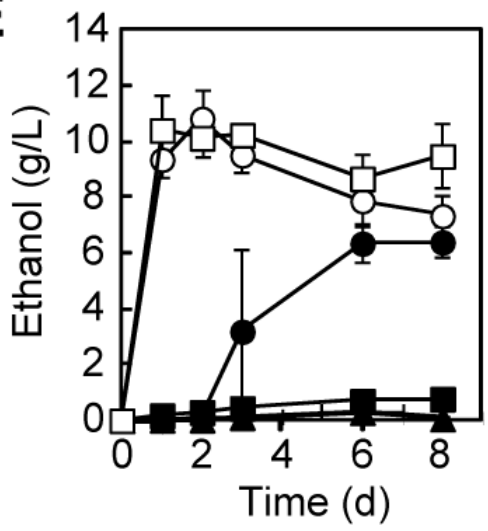

FIG. 2. 
A

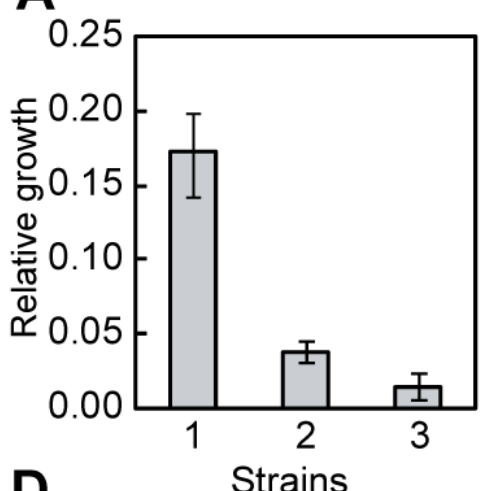

D
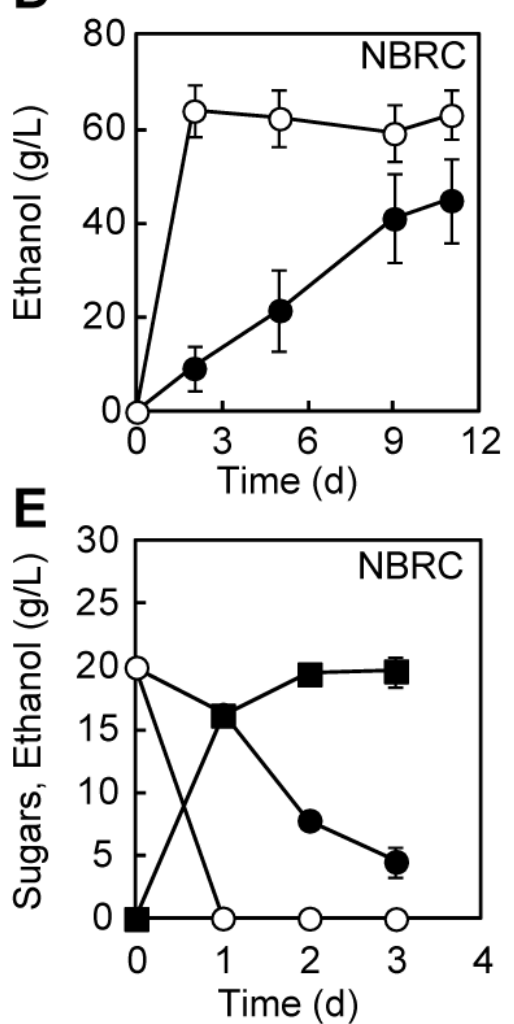

B
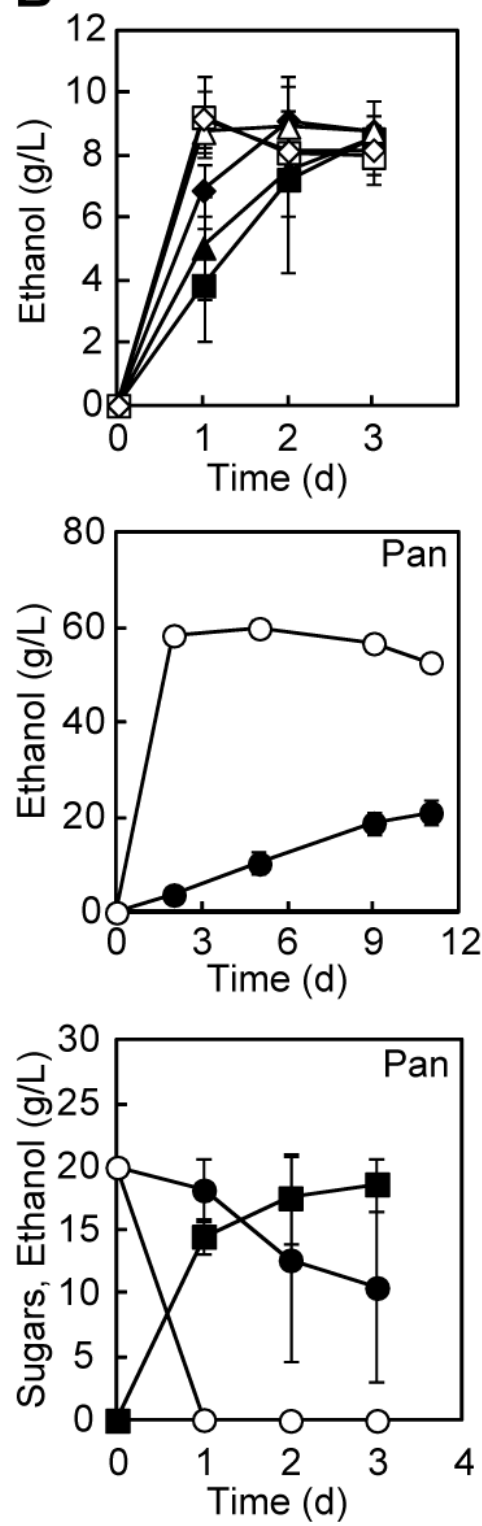

C
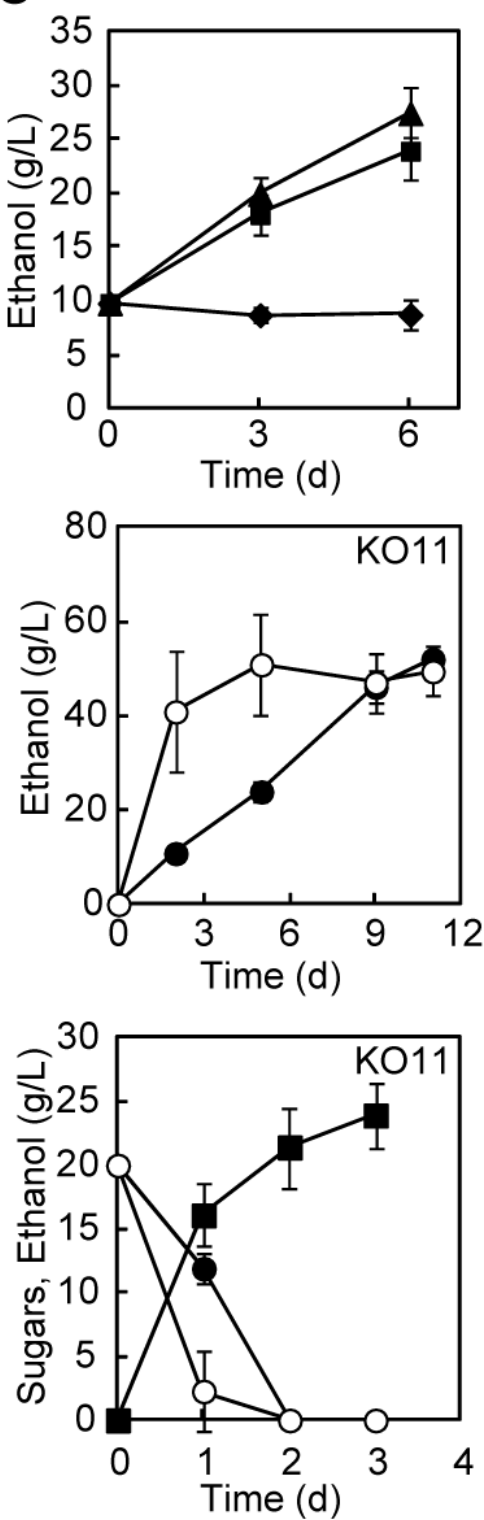

FIG. 3. 
TABLE 1. Yeast strains used in this study

\begin{tabular}{|c|c|c|c|c|}
\hline Yeasts $^{a}$ & $\begin{array}{l}\text { AKU } \\
\text { No. }\end{array}$ & $\begin{array}{l}\text { Other } \\
\text { No. }\end{array}$ & Growth ${ }^{b}$ & Ethanol ${ }^{\mathrm{c}}$ \\
\hline Saccharomyces cerevisiae BY4742 & & $\begin{array}{c}\text { ATCC } \\
201389\end{array}$ & - & - \\
\hline American yeast (Fleischmann baker's yeast) & 4001 & & - & - \\
\hline American yeast (American whiskey yeast) & 4004 & & - & - \\
\hline Saccharomyces sake Chuyu & 4011 & & - & - \\
\hline Saccharomyces sake Hozan & 4013 & & - & - \\
\hline Saccharomyces sake Ozeki & 4014 & & - & - \\
\hline Saccharomyces sake Sakaizumi & 4016 & & - & - \\
\hline Saccharomyces sake Fukumusume & 4017 & & - & - \\
\hline Saccharomyces sake Unryu & 4019 & & - & - \\
\hline Saccharomyces sake Sawanotsuru & 4022 & & - & - \\
\hline Wine yeast & 4036 & & - & - \\
\hline Beer yeast (Kirin) & 4037 & & - & - \\
\hline Baker's yeast (Oriental) & 4039 & & - & - \\
\hline München beer yeast & 4042 & & - & - \\
\hline Saccharomyces carlsbergensis & 4044 & & - & - \\
\hline Saccharomyces cerevisiae & 4100 & & - & - \\
\hline Saccharomyces logos & 4101 & & - & - \\
\hline Kazachstania unispora & 4106 & $\begin{array}{c}\text { NBRC } \\
0215\end{array}$ & - & - \\
\hline Saccharomyces fragilis & 4108 & $\begin{array}{c}\text { IFO } \\
0228\end{array}$ & - & - \\
\hline Saccharomyces sp. & 4110 & & - & - \\
\hline Naumovozyma castellii & 4111 & & - & - \\
\hline Saccharomyces cerevisiae & 4136 & $\begin{array}{c}\text { NBRC } \\
1346\end{array}$ & - & - \\
\hline Saccharomyces cerevisiae & 4150 & $\begin{array}{l}\text { IAM } \\
4512\end{array}$ & - & - \\
\hline Schizosaccharomyces pombe & 4220 & $\begin{array}{c}\text { NBRC } \\
0346\end{array}$ & - & - \\
\hline Saccharomyces paradoxus & 4135 & $\begin{array}{c}\text { NBRC } \\
0259\end{array}$ & + & + \\
\hline Zygosaccharomyces japonicus & 4242 & $\begin{array}{c}\text { IFO } \\
0595\end{array}$ & + & - \\
\hline Pichia polymorpha & 4250 & $\begin{array}{c}\text { IFO } \\
0195\end{array}$ & + & - \\
\hline Pichia farinosa & 4262 & $\begin{array}{c}\text { NBRC } \\
0193\end{array}$ & + & - \\
\hline Pichia haplophila & 4263 & $\begin{array}{c}\text { NBRC } \\
0947\end{array}$ & + & - \\
\hline Pichia saitoi & 4266 & $\begin{array}{l}\text { IAM } \\
4945\end{array}$ & + & - \\
\hline Hansenula saturnus & 4301 & $\begin{array}{c}\text { IFO } \\
0177\end{array}$ & + & - \\
\hline Kuraishia capsulata & 4305 & $\begin{array}{c}\text { NBRC } \\
0721\end{array}$ & + & + \\
\hline
\end{tabular}


Wickerhamomyces silvicola

Kuraishia capsulata

Ogataea glucozyma

Ogataea minuta

Debaryomyces hansenii

Debaryomyces hansenii

Naumovia castellii

Hanseniaspora valbyensis

Sporidiobolus salmonicolor

Yarrowia lipolytica

Yarrowia lipolytica

Candida solani

Candida albicans
4313

NBRC

0807

4326 NBRC

0974

$4330 \quad$ NBRC

1472

4332 NBRC

1473

4357 IFO

0023

4359 NBRC

0794

4127 NBRC

0285

$4405 \quad$ NBRC

0115

$4440 \quad$ NBRC

1035

$4598 \quad$ NBRC

0746

$4599 \quad$ NBRC

1195

4612 NBRC

0762

$4633 \quad$ NBRC

${ }^{\text {a }}$ These strains were maintained on YPD solid medium, suspended in SDW, added to $1.0 \mathrm{ml}$ liquid medium in a test tube to an $\mathrm{OD}_{600}$ of 0.1 , and cultivated at $30^{\circ} \mathrm{C}$ without shaking for 3 days.

${ }^{\mathrm{b}}$ Strains that exhibited better growth on SM solid and liquid media than on SC-C media are shown by plus (+); strains that did not show better growth on SM media than SC-C media are by minus (-).

${ }^{\mathrm{c}}$ Ethanologenic yeasts that produced ethanol after 3 days of cultivation in SM liquid medium are indicated by plus $(+)$; yeast that produced no ethanol in this condition are by minus (-). 
TABLE 2. Comparison of ethanol production

\begin{tabular}{|c|c|c|c|c|c|c|}
\hline Strains & Substrate ${ }^{a}$ & $\begin{array}{l}\text { Cultivation } \\
\text { time }(\mathrm{h})^{\mathrm{b}}\end{array}$ & $\begin{array}{c}\text { Substrate } \\
\text { consumption }(\mathrm{g} / \mathrm{L})^{\mathrm{c}}\end{array}$ & $\begin{array}{l}\text { Ethanol production } \\
(\mathrm{g} / \mathrm{L})^{\mathrm{d}}\end{array}$ & $\begin{array}{l}\text { Productivity } \\
(\mathrm{g} / \mathrm{L} / \mathrm{h})(=\mathrm{d} / \mathrm{b})\end{array}$ & $\begin{array}{c}\text { Yield } \\
(\mathrm{g} \text { ethanol } \\
\text { /g substrate })(=\mathrm{d} / \mathrm{c})\end{array}$ \\
\hline S. paradoxus NBRC 0259 & Mannitol & 120 & 20.0 & 7.3 & 0.06 & 0.36 \\
\hline K. capslata NBRC 0721 & Mannitol & 120 & 14.0 & 2.6 & 0.02 & 0.19 \\
\hline K. capslata NBRC0974 & Mannitol & 120 & 7.6 & 1.2 & 0.01 & 0.15 \\
\hline O. glucozyma NBRC 1472 & Mannitol & 120 & 10.2 & 2.1 & 0.02 & 0.21 \\
\hline O. minuta $\mathrm{NBRC} 1473$ & Mannitol & 120 & 6.7 & 3.5 & 0.03 & 0.52 \\
\hline D. hansenii NBRC 0794 & Mannitol & 120 & 4.6 & 0.1 & 0.00 & 0.02 \\
\hline S. paradoxus NBRC 0259-3 & Mannitol & 72 & 20.0 & 8.9 & 0.12 & 0.44 \\
\hline P. angophorae & Mannitol & 72 & 20.0 & 9.3 & 0.13 & 0.46 \\
\hline E. coli KO11 & Mannitol & 72 & 20.0 & 9.2 & 0.13 & 0.46 \\
\hline S. paradoxus NBRC 0259-3 & Glucose & 24 & 20.0 & 10.2 & 0.43 & 0.51 \\
\hline P. angophorae & Glucose & 24 & 20.0 & 11.5 & 0.48 & 0.57 \\
\hline E. coli $\mathrm{KO} 11$ & Glucose & 24 & 20.0 & 11.0 & 0.46 & 0.55 \\
\hline
\end{tabular}

${ }^{\mathrm{a}}$ Initial concentration of substrate is $20 \mathrm{~g} / \mathrm{L}$.

${ }^{b}$ The cultivation time at which the highest concentration of ethanol was produced.

${ }^{\mathrm{c}}$ Substrate consumed during the cultivation time (b).

${ }^{\mathrm{d}}$ Ethanol produced during the cultivation time (b). 